\title{
An Empirical Study of The Improper Pronunciation of Trisyllabic Verbs by Iraqi EFL Learners
}

\author{
Dr. Mukhalad Malik Department of English \\ Cihan University/ Sulaimaniya
}

\begin{abstract}
Syllables in English are one of the most important topics that play a major role in mastering an efficient performance of the way English words are pronounced. Syllables in English vary according to the centres they may have but the way of their pronunciation might be of certain difficulty for EFL for certain phonological inefficiencies. The paper attempts at investigating the improper pronunciation of trisyllabic words empirically through presenting EFL learners a group of words containing three syllables so as to elicit the way they pronounce such words. The study reveals that Iraqi EFL learners face difficulty while pronouncing such words. It shows in detail that they fail while trying to pronounce trisyllabic words. Such inappropriateness is mainly due to certain phonological attributes including placement of stress, unfamiliarity of trisyllabic words and other related points.
\end{abstract}

Key words: syllable, trisyllabic verbs, stress placement, improper pronunciation

\section{INTRODUCTION}

The syllable is essentially an important unit both in phonetics and in phonology. From the speech production point of view a syllable consists of a movement from a knotted or silent position to a vowel-like position and then back to knotted or silent. Syllables are claimed to be the most basic unit in speech: every language has syllables which play a major role in understanding the meaning properly if they are pronounced appropriately. The current study aims investigating the improper pronunciation of a kind of syllable called trisyllabic verbs (verbs containing three syllables) by Iraq EFL learners. It is believed that learners face difficulty when pronouncing such words due to certain phonological attributes among which is the wrong placement of stress, improper pronunciation of certain vowels which the syllable may contain and other phonological inefficiencies. All of this may lead to improper pronunciation and thus, learners may fail to communicate efficiently regarding the performance of trisyllabic verbs. To verify the aims of the study, a group of words containing three syllables are given to a sample of learners so as to identify the improper pronunciation. The words are chosen from Roach's book 'English Phonetics and Phonology' as the modal of analysis.

\section{AN INTRODUCTION TO SYLLABLE}

To start with illustrating what syllable is, it is significance to state the fact that a syllable contains vowel and consonants and both have certain functions in the syllable in which they occur. In general, it could be stated that a syllable must have a vowel as the centre and consonants surrounding it, preceding or cutting it off (Kenworthy, 1987). So basically, a syllable must contain a vowel and consonant(s) preceding or following it. Crystal (2003:447) defines a syllable as " a unit of pronunciation typically larger than a single sound and smaller than a word. The notion of syllable, in short, is very real to native speakers, and is often used in a quasi technical sense in everyday conversation'. The syllable is a basic unit of speech studied on both the phonetic and phonological levels of analysis. Phonetically syllables "are usually described as consisting of a centre which has little or no obstruction to airflow and which sounds comparatively loud; before and after that centre (...) there will be greater obstruction to airflow and/or less loud sound" (Roach, 2009: 56). In the monosyllable (onesyllable word) cat $/ \mathrm{kæt} /$, the vowel /æ/ is the "centre" at which little obstruction takes place, whereas we have complete obstruction to the airflow for the surrounding plosives / $\mathrm{k} /$ and $/ \mathrm{t} /$. Laver (1994: 114) defines the phonological syllable as "a complex unit made up of nuclear and marginal elements". Nuclear elements are the vowels or syllabic segments; marginal elements are the consonants or non-syllabic segments. In the syllable paint /peint/, the diphthong /eI/ is the nuclear element, while initial consonant $/ \mathrm{p} / \mathrm{and}$ the final cluster $/ \mathrm{nt} / \mathrm{are}$ marginal elements. According to the prominence theory, for example, which is based mainly on auditory judgements, the number of syllables in a word is determined by the number of peaks of prominence. In the word entertaining /, entə'ternıy/ the peaks of prominence are represented by the vowels /e ə eI I/. However, this theory does not help much in discussions of syllable division. 


\section{THE SYLLABLE STRUCTURE}

The bulk of present-day phonological theory agrees that the syllable has constituent or hierarchical, rather than linear, structure. The syllable (has two immediate constituents which includes any consonants that precede the nuclear element (the vowel), and the Rhyme (R), which subsumes the nuclear element (the vowel) as well as any marginal elements (consonants) that might follow it. The Rhyme, in turn, further branches into Peak (P), also known as Nucleus (N), and Coda (Co). The Peak (Nucleus), as the designation suggests, represents the "nuclear" or most sonorous element in a syllable. The Coda includes all consonants that follow the Peak in a syllable (Giegrich, 1992). The structure of the English syllable is, thus, mainly concerned with possible and permissible combinations of phonemes in English.

This is related to what is called consonant cluster; the possible occurrences of consonants in initial and final positions within syllables (Roach, 2009). What is significant to state and in relation to the scope of the current paper, is the fact that words containing more than one syllable (more than one centre) should be divided in both transcription and pronunciation so as to get a better pronunciation. As far as possible, syllables should not be divided in a way that violates what is known of English syllable structure. The 'Maximal Onsets Principle', which is widely recognised in contemporary phonology, is followed as far as possible. This means that, where possible, syllables should be divided in such a way that as many consonants as possible are assigned to the beginning of the syllable to the right (if one thinks in terms of how they are written in transcription), rather than to the end of the syllable to the left (Jones, 1997). However, when this would result in a syllable ending with a stressed /I/, /e/, /æ/, / $/, / \mathrm{p} /$ or $/ \mho /$, it is considered that this would constitute a violation of English phonotactics, and the first (or only) intervocalic consonant is assigned to the preceding syllable; thus the word 'better' is divided/'bet.ə/, whereas 'beater' is divided/'bi:.tər/. In the case of unstressed short vowels, /e/, /æ/, $/ \Lambda /$ and $/ \mathrm{p} /$ are also prevented from appearing in syllable-final position; however, unstressed /I/ and / $/$ are allowed the same "privilege of occurrence" as /o/ when a consonant begins a following syllable, and may therefore occur in final position in unstressed syllables except pre-pausally. Thus in a word such as 'develop', the syllable division is /di'vel.əp/ (ibid). The other significant issue related to the aims of the present work is stress placement within words containing more than one syllable (monosyllable, disyllable and so on). This is entirely related to the fact that in English, stress placement is a major factor in identifying which stress is stressed and which is not and on what basis. Knowing where to place stress on syllables result into an efficient pronunciation of the words and hence the meanings will be clear when using such words.

In this respect, O'Connor (1980) state that words in English containing more than one syllable have certain places of stress; one of the syllables is stressed whereas the other is not stressed as in the word 'father' where the first syllable / fæ/ is stressed and the other / ðə/(where the star represents a stressed syllable). So, words having more than one syllable are stressed on certain syllables according to certain phonological rules. But what about stress itself? It can be stated that stress refer to the fact that all syllables which are stressed must be prominent (high-up pronunciation). By prominence, stressed syllables tend to be louder than unstressed syllable, so stress is a matter of producing the syllable with louder pronunciation (Roach, 2009).

\section{TRISYLLABIC VERBS}

Crystal (2003: 497) defines trisyllable as "A term used in phonetics and phonology to refer to a unit, typically a word, consisting of three syllables, such as consequence and happily; it contrasts with monosyllable and disyllable. A trisyllabic form is distinguished from monosyllabic and disyllabic forms'". Since the current study deals with verbs only, the analysis would only comprises trisyllabic verbs; verbs which contain three syllables only. If trisyllabic verb contains three syllables, then, as mentioned earlier, one of its syllables is stressed and the others may be unstressed or receive the secondary stress. The rules of placing stress within trisyllabic verbs differ according to specific rules. In simple verbs, if the final syllable is strong, then it will be stressed which measn that it is pronounced loudly than the other syllables as in entertain /Into'teIn/ where the phonetic symbol " refers to a stressed syllable(Roach, 2009). Certainly the quality of the vowel (whether long or short, diphthong or triphthong and son) influences the stress itself where sometimes if the last syllable of the verb is weak, the penultimate syllable will be stressed. This means that the first and the last are unstressed and the second is stressed as in determine /dI't3:mIn/ (Chomsky et, al. 1968). This latter rule is also discussed by Roach who states that "if the last syllable is weak, then it will be unstressed, and stress will be placed on the preceding (penultimate) syllable if that syllable is strong. Thus: encounter /In'kavtə/" (Roach: 78). In some instances, the second and the third syllables of the trisyllabic verbs are unstressed; they are weak due to the occurrence of weak vowels or syllabic consonants (as it is considered a weak syllable). In this case, the initial syllable (the first) is stressed as in parody /'pærədi/ (ibid). It is very important to know such rules as they represent the efficient pronunciation and thus considered important in communication so as to understand and to be understood. This clearly shows that concerning the trisyllabic verbs the stress is not an optional extra that one can add to the English language. It is part of the language. English speakers use word stress to communicate rapidly and accurately, even in difficult conditions as when the words contain more than two syllables. If, for 
example, one does not hear a word clearly, it is possible to understand the word because of the position of the stress.

\section{METHODOLOGY}

To verify the aims of the study, a test is designated to elicit the pronunciation of trisyllabic verbs so as to determine the inappropriateness of the pronunciation of such words by Iraqi EFL learners. The test contains a group of words to be read by those learners ( $4^{\text {th }}$ year stage) who are majoring English as a foreign language in the department of English / Cihan University/ Sulaimaniya. All the words are chosen from Roach's book 'English Phonetics and Phonology' and certainly they are trisyllabic words having the same stressed rules discussed in the previous section. The pronunciations of those verbs are recorded so as to identify the improper pronunciation of each. There is no doubt that the pronunciation of the verbs is entirely compared to the transcriptions of the chosen words so as to have an efficient results and analysis. All the words chosen as the items of the test are trisyllabic verbs following the same aforementioned rules of stress placement as in the following:

resurrect /rezə'rekt/, entertain /Intə'teIn/ ,encounter /In'kautə/, determine /dI't3:mIn/, parody /'pærədi/, monitor /'mpnitə/.

\section{RESULTS AND DATA ANALYSIS}

All the pronunciations of trisyllabic verbs are recorded so as to identify the improper pronunciations concerning the stress placement and other related phonetic inefficiencies. The results of the test refer to the occurrence of improper pronunciation of the verbs which contain three syllables. Such improper pronunciation can be attributed to certain phonological and phonetic features the most important of which is the improper stress placement and, in some instances, the improper pronunciation of certain sounds. In all cases, such inappropriateness result into awkward and wrong pronunciation of the trisyllabic verbs and, consequently, the pronunciation of the given verb would be unclear and does not match the exact pronunciation. The first phonological inappropriateness is reflected by the fact that learners, while attempting at pronouncing the verbs, do not recognize that stress is to be placed on specific syllable and it is not a matter of one's choice at all. In such case the stress is placed according to the learner's own judgement not according to the exact placement of the stress. This is attributed to the possibility that the learners don't know which syllable should be stressed (pronounced louder than the other syllables); they have no knowledge about the rules of stress placement within trisyllabic verbs. Another possibility is that learners may have knowledge about rules of stress but such knowledge is inefficient. In both cases, the result is improper pronunciation as in the following instances (where the words are transcribed according to the way the learners pronounced them after hearing them several times and the stress is placed on the syllable that is produced louder by the learners): entertain /'IntəteIn/, encounter /'Inkavtə/, determine /dIt3:'mIn/, parody /'pær'ədi/, monitor /mb'nitə/. Those instances clearly show the improper placement of stress and thus the improper pronunciation of such verbs. The improper pronunciation that is found in the data can also be attributed to the fact that, in some instances, learners had very power knowledge of pronunciation of the entire trisyllabic verb including stress placement and the proper pronunciation of the vowels which those verb contain as in the following examples (where the transcription are carefully made according to the way the learners pronounced them and the stress is placed on the syllable that is produced louder by the learners): resurrect /'rezərıkt/, entertain /'Intəti:n/,encounter /inku:'tə/, parody /pp'rədi/, monitor /'mbnitə/. Once again, such improper pronunciation is considered entirely a deviation from the exact one and the result is meaningless words to a certain extent. In some cases, the stress placement is proper but the pronunciation of certain vowels is not proper at all where learners used various vowels which do not match the exact one.

\section{CONCLUSION}

Trisyllabic verbs are words which contain three syllables and have specific rules of stress placement. The proper pronunciation of such verbs reflects an efficient knowledge of the way they are pronounced and hence their use in communication would understandable and clear. When Iraqi EFL learners pronounce trisyllabic verbs, they deviate due to the improper placement of stress and also due to the improper pronunciation of specific vowels that those verbs contain. Such deviation or inappropriateness is mainly due to lack of phonological rules of stress placement and to a certain extent lack of the exact pronunciation of certain vowels. The resulting improper pronunciation makes those trisyllabic verbs unclear when used in certain communicative events. In fact, an efficient knowledge of stress placement within three syllable words and an efficient knowledge of vowels are prerequisite in mastering a better pronunciation which is an essential factor if an efficient communication is to be achieved.

\section{BIBLIOGRAPHY}

[1] Chomsky, Noam, and Halle, M. (1968). The sound pattern of English. New York: Harper and Row. 
[2] Crystal, David (2003). A Dictionary of Linguistics and Phonetics. Oxford: Blackwell Publishing.

[3] Giegrich, H.(1992). English Phonology. An Introduction. Cambridge: Cambridge University Press.

[4] Jones, D. 1997. Edited and revised by P. Roach and J. Hartman. English Pronouncing Dictionary. Cambridge: Cambridge University Press.

[5] Kenworthy, J. (1987). Teaching English Pronunciation. Harlow: Longman.

[6] Laver, J. (1994). Principles of Phonetics. Cambridge: Cambridge University Press.

[7] O’Cconor, J., D. (1980). Better English Pronunciation. Cambridge: Cambridge University Press.

[8] Roach, Peter. (2009). English Phonetics and Phonology. A Practical Course. Cambridge: Cambridge University Press. 